\title{
Formação e o trabalho profissional em Serviço Social frente aos desafios da mercantilização da Política de Educação Superior no Brasil
}

\author{
Training and professional work in Social Work \\ in front of the challenges of mercantilization of \\ Higher Education Policy in Brazil
}

\author{
Fabricia Cristina de Castro Maciel ${ }^{*}$ \\ Eliana Bolorino Canteiro Martins ${ }^{\star \star}$
}

\begin{abstract}
Resumo: Este estudo é resultado de levantamento bibliográfico e documental que pretende apresentar reflexões quanto às tendências da formação e do trabalho profissional em Serviço Social no contexto contemporâneo, sob a lógica do reordenamento econômico e político do capital, a partir da análise da categoria trabalho. Identificamos o trabalho da(o) assistente social no campo dos serviços e as condições em que o labor intelectual se insere na lógica da produção e distribuição do valor e da reprodução social da vida. A partir da perspectiva ontológica, procuramos compreender os processos de dominação política e econômica do sistema do capital e as mediações desenvolvidas pelas políticas sociais, situando nesse contexto o contraditório significado social da profissão. Destacamos os desafios da formação em Serviço Social frente à mercantilização da política de educação superior, bem como do exercício profissional crítico e comprometido com a classe trabalhadora, em consonância com o projeto ético-político profissional.
\end{abstract}

Palavras-chave: Formação em Serviço Social. Trabalho. Política de Educação Superior.

Abstract: This study is the result of a bibliographic and documentary survey that aims to present reflections on the trends of training and professional

\footnotetext{
+ Doutorado em Serviço Social pela Universidade Estadual Paulista Júlio de Mesquita Filho - UNESP (2020), com sanduíche na Universidade de Lisboa, Instituto Superior de Ciências Sociais e Políticas. Mestrado em Administração Pública/Gestão de Políticas Sociais pela Escola de Governo de Minas Gerais/Fundação João Pinheiro (2005) e especialização em Educação Sexual pela FUMEC (1998). Graduação em Serviço Social pela Pontifícia Universidade Católica de Minas Gerais (1994). Professora no Centro Universitário UNA. Email: fabriciacm@gmail.com.

** Doutorado em Serviço Social pela Pontifícia Universidade Católica de São Paulo - PUC/SP (2007), mestrado em Serviço Social pela Universidade Estadual Paulista Júlio de Mesquita Filho (UNESP) Faculdade de Ciências Humanas e SociaisCampus Franca (2001) e graduação em Serviço Social pela Faculdade de Serviço Social - Instituição Toledo de Ensino de Bauru (1983). Pós-doutorado (atual) pela Universidade Estadual do Rio de Janeiro (UERJ). Professora do Curso de Serviço Social da UNESp/Franca. E-mail: elianacanteiro@terra.com.br.
}

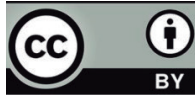

This content is licensed under a Creative Commons attribution-type BY 
work in Social Work in contemporary context, under the logic of economic and political rearrangement of capital, from the analysis of labor category. We identified the work of social worker in the field of services and the conditions in which intellectual work is inserted in the logic of the production and distribution of value and the social reproduction of life. From the ontological perspective, we seek to understand the processes of political and economic domination of the capital system, and the mediations developed by social policies, placing in this context the contradictory social meaning of the profession. We highlight the challenges of training in Social Work in view of the commercialization of higher education policy, as well as the critical professional exercise and committed to the working class, in line with the professional ethical-political project.

Keywords: Training in Social Work. Labor. Higher Education Policy.

Submetido: em 10/02/2020. Aceito em: 08/06/2020

\section{INTRODUÇÃO}

Este artigo trata-se de um contributo do processo de doutoramento em Serviço Social pela Universidade Estadual Júlio de Mesquita Filho (UNESP/Franca) e tem por objetivo apresentar elementos para identificar as tendências da formação e do trabalho da(o) assistente social considerando a nova configuração do modo de produção e reprodução capitalista, que traz implicações ao mundo do trabalho e da educação, marcado pelo processo de mercantilização da política educacional superior no Brasil. Para tanto, realizamos pesquisa bibliográfica e documental, utilizando autoras(es) clássicas(os) da literatura histórico-crítica. Definimos como ponto central deste estudo o imperativo de uma formação que requer competências ontológicas e reflexivas para a atuação profissional e reconhecemos a categoria trabalho como fundante das determinações que incidem na práxis das(os) assistentes sociais de um país de economia dependente.

Nesse sentido, nossas análises partem da teoria do valor-trabalho no modo de produção capitalista para a compreensão referente à forma peculiar de socialização do trabalho coletivo e da apropriação da força de trabalho ${ }^{1}$, no contexto da mundialização do capital (CHESNAIS, 1996). Esse percurso contribuiu para identificarmos as contradições impostas pelo mundo do trabalho e as mediações ${ }^{2}$ do campo profissional do Serviço Social nas diversas esferas de atuação. Conforme afirma Iamamoto (2003, p. 27), o Serviço Social “[...] é considerado como uma especialização do trabalho, e a atuação do assistente social, uma manifestação de seu trabalho, inscrito no âmbito da produção e reprodução da vida”. É na divisão sociotécnica do trabalho, de forma assalariada,

\footnotetext{
${ }^{1}$ Por força de trabalho ou capacidade de trabalho, compreendemos o conjunto das faculdades físicas e mentais existentes no corpo e na personalidade viva de um ser humano, as quais ele põe em ação toda vez que produz valores de uso de qualquer espécie (MARX, 2008, p. 197).

${ }^{2}$ Categoria de análise da realidade cuja paternidade intelectual deve-se a Hegel. Segundo afirma Pontes (2000), mediação é um construto que a razão elabora logicamente para possibilitar a apreensão do movimento do objeto. A mediação possui dupla dimensão: uma ontológica - que pertence ao real - e outra, reflexiva.
} 
que as(os) profissionais do Serviço Social apreendem e enfrentam, no cotidiano, as expressões da questão social que emergem da diferenciação e conflitos das classes sociais.

Portanto, a problematização realizada sob as evidências da ontologia considera tanto a direção política hegemônica da profissão quanto os determinantes estruturais do mundo do trabalho, articulando o padrão de formação em Serviço Social com as requisições impostas pelos empregadores dessa categoria. Ou seja, na relação entre a formação profissional dispensada à classe trabalhadora e o tipo de trabalho exigível e disponível nos países de capitalismo dependente (mas não somente neles), estabelecem-se subsunções que configuram a atual reestruturação produtiva ${ }^{3}$, caracterizada pela flexibilização das regras trabalhistas e do perfil profissional, enxugamento e aligeiramento dos processos de trabalho, tarefismo e pragmatismo no exercício das profissões. Além disso, conforme trata Antunes (2020) os elementos estruturantes do sistema do capital vem ampliando a desigualdade social e o desemprego, bem como submetendo a classe trabalhadora a mais espoliação e maior exploração.

\section{A CATEGORIA TRABALHO: AS RELAÇÕES SOCIAIS DE PRODUÇÃO E REPRODUÇÃO DA VIDA}

Iniciamos nossos argumentos a partir das elaborações apresentadas principalmente por estudiosos, como Karl Marx, György Lukács, Sadi Hirano, Issak Rubin e Ricardo Antunes, que percorrem um caminho de análises da sociedade pautadas na teoria social crítica marxiana e marxista, e contribuem para o entendimento mais alargado da concepção de trabalho como categoria fundante do ser social. No campo específico do Serviço Social, as reflexões de Marilda Iamamoto e José Paulo Netto, entre outros teóricos que estão em nosso horizonte ${ }^{4}$, foram fundamentais para desenvolvermos a tessitura da unidade entre trabalho e formação profissional em Serviço Social. Para Marx (2008, p. 62-63), “[...] o trabalho é condição natural da existência humana, a condição, independentemente de todas as formas sociais, do intercâmbio da matéria entre o homem e a natureza". É por meio do trabalho que o homem (lê-se sempre humanidade) atua sobre a natureza, transformando-a e modificando sua própria natureza. Assim, desenvolve suas potencialidades, considerando que, diferentemente dos demais animais, o homem possui capacidade de projeção ou ideação do processo e do resultado do seu trabalho. Em cada tempo histórico, a humanidade produz objetos que respondem às suas necessidades e desejos, sendo que os meios e as formas da produção vão se distinguindo. Assim também as profissões surgem e se estruturam considerando as exigências das condições e relações sociais em que vivemos, construídas por homens e mulheres.

Marx (2008) traz elementos para analisar que, na sociedade capitalista, há uma dupla determinação do trabalho, ou seja, o trabalho concreto e o trabalho abstrato. Os estudos de Eduardo Chagas (2012) contribuem para o entendimento dessas acepções ao afirmar que o trabalho concreto é denominado como positivo, como objetivação e autodesenvolvimento humano, automediação entre o homem e a natureza e entre o homem e o homem. Portanto, é trabalho vivo, que

\footnotetext{
${ }^{3}$ Destaca-se, de acordo com Tumolo (1997), que há um consenso entre diversos estudiosos de uma tendência ao esgotamento ou, pelo menos, o questionamento do modelo clássico taylorista/fordista de organização da produção a partir dos anos 1970, e decorrente da emergência de novos "modelos" "Terceira Itália”, Suécia, Alemanha, Vale do Silício - EUA, Japão etc.), sendo o "modelo" japonês, ou ohnoismo/ toyotismo, o que vem recebendo maior atenção e o mais discutido. Somase à estrutura política neoliberal de organização dos Estados.

${ }^{4}$ Explicitados ao longo deste estudo e nas referências bibliográficas.
} 
produz valor de uso (utilizável), indispensável à produção e reprodução humana. Por sua vez, o trabalho abstrato, negativo, denominado "trabalho morto", contido nas mercadorias, tem por principal fim a criação de mais-valor, ou seja, valorização do valor, a reprodução e autovalorização do capital. Afirma Marx (2008) que a utilização da força de trabalho humana, ao constituir-se de uma utilidade e uma necessidade determinada, passa a adquirir valor de uso. A força de trabalho humana em ação torna-se valor "[...] quando se cristaliza na forma de um objeto" (MARX, 2008, p. 73). Assim, "O produto é um valor de uso, um material da natureza adaptado às necessidades humanas através da mudança de forma. 0 trabalho está incorporado ao objeto sobre que atuou" (MARX, 2008, p. 214). No entanto, é por meio do dispêndio de força humana de trabalho, no sentido fisiológico, na qualidade de trabalho abstrato, que ele gera o valor das mercadorias. Cabe observar, de acordo com os postulados de Marx (2008, p. 83), que "[...] em todos os estágios sociais, o produto do trabalho é valor de uso". É no momento em que ele se torna passível de ser vendido a um proprietário, em que o ser humano despende sua força de trabalho para a produção de coisa útil, que terá valor de troca, e que seu produto se transforma em mercadoria. Uma mercadoria passa a ter valor ou adquire valor de uso quando apresenta um componente de universalidade alienável para que a forma de valor de troca também seja universalizante, sendo que o "valor de troca de uma mercadoria varia com a quantidade de tempo de trabalho a ela incorporada" (MARX, 2008, p. 67). Portanto, ressalta-se, em nossa acepção, que o produto do trabalho humano não tem que ser necessariamente tangível (cadeira, garrafa etc.), uma vez que a própria força de trabalho torna-se mercadoria - especial, pois é a única mercadoria que cria valor, conforme reforça Antunes (2020, p. 16), estando na base de toda a produção.

Portanto, o que irá caracterizar o capital e distinguir a forma de produção capitalista das anteriores é a relação de personificação de coisas e a coisificação de pessoas. Torna-se essencial para este estudo compreender a força de trabalho como mercadoria de natureza peculiar, que se desenvolve em diversos ramos da produção. Com esse alcance, identificamos que o trabalho da(o) assistente social situa-se no setor de serviços e não produz diretamente mercadorias (produtos), mas contribui para a lógica da reprodução da força de trabalho. Destacamos, pois, que o trabalho dessa categoria, ao inserir-se no setor de serviços tanto privado como público diferencia-se no que diz respeito à geração de mais-valor, sendo que, na primeira condição, isso ocorre, e na outra, não. Para melhor exemplificar essa ideia, buscamos em Marx, na obra $O$ Capital, tal evidência ao abordar que "A mesma aula é produtiva de valor ao ser proferida numa escola particular que visa ao lucro, mas deixa de o ser quando ministrada numa escola pública" (MARX, 2008, p. 101). Essa diferença apresentada por Marx nos oferece algumas pistas para melhor desvelar a atividade laboral da(o) assistente social. Ou seja, o trabalho dessa(e) profissional tem similaridades com a do(a) professor(a), uma vez que a atividade laboral das duas profissões incidem de forma direta na manutenção do sistema do capital. No processo de internalização (expressão de Mészáros, 2008) da dinâmica do capital, exige-se desses profissionais um trabalho de natureza intelectual com a finalidade de naturalização e manutenção dos fundamentos capitalistas. Na divisão sociotécnica do trabalho, a(o) assistente social, tal como a(o) professor(a), ocupam-se da função intelectual de mediação das contradições do sistema do capital, resguardadas as devidas diferenças entre essas ocupações. A partir dessa relação, podemos inferir que o trabalho no âmbito do Serviço Social terá sempre natureza intelectual ${ }^{5}$ e função educativa, sendo que, na perspectiva histórico-crítica, assentar-se-ia o propósito de contribuir para a construção de uma nova sociabilidade,

\footnotetext{
${ }^{5}$ Reforçamos que o trabalho intelectual expressa-se de forma particular, todavia, toda a sua produção e construção ideologizada é sempre coletiva, pois é derivada exclusivamente de uma prática social. Por outras palavras, não há nada nos seres sociais que não seja mediado, ou seja, uma prática linguística no sentido mais amplo e geral.
} 
livre de opressões e explorações de classe, gênero e etnia. Por sua vez, na prestação de serviços sociais, tais natureza e função podem resvalar para uma prática disciplinadora, reprodutivista e conservadora, a depender do cariz da formação das(os) profissionais.

Portanto, no sistema do capital, o modo e as condições de produção e a forma de apropriação da força de trabalho determinam como um coletivo de trabalhadores coloca-se e se reconhece no processo produtivo. Nesse sentido, Iamamoto nos apresenta uma valiosa contribuição com a seguinte reflexão:

Então, o Serviço Social é um trabalho especializado, expresso sob a forma de serviços, que tem produtos: interfere na reprodução material da força de trabalho e no processo de reprodução sociopolítica ou ideopolítica dos indivíduos sociais. O assistente social é, neste sentido, um intelectual que contribui, junto com inúmeros outros protagonistas, na criação de consensos na sociedade. Falar em consenso diz respeito não apenas à adesão ao instituído: é consenso em torno de interesses de classes fundamentais, sejam dominantes ou subalternas, contribuindo no reforço da hegemonia vigente ou criação de uma contra-hegemonia no cenário da vida social (IAMAMOTO, 2003, p. 69).

O trabalho intelectual, também apropriado e comandado pelo capital, além de produzir conhecimento técnico-científico para a ampliação e inovação dos processos de trabalho, gera a produção de elementos ideológicos que reforçam a reprodução da dominação política, social e econômica das elites. Cabe ressaltar que, no contexto do processo de redemocratização política brasileira dos anos de 1980, a(o) trabalhador assistente social já assumira uma nova postura e direção social expressa no seu projeto ético-político, tendo o compromisso de atuação nas classes assalariadas subalternas ao capital. Ocupa assim, preferencialmente, o campo das mediações instauradas pelas políticas públicas, sem deixar de contribuir com a autovalorização do capital, em medidas distintas de atuação nos setores públicos e privados, conforme contradição anteriormente explicitada. Nessa direção, abordamos as determinações do mundo do trabalho frente às tendências formativas que vêm desenvolvendo-se no processo de mercantilização da educação no contexto atual.

\section{O TRABALHO NOS PROCESSOS DE DOMINAÇÃO POLÍTICA E ECONÔMICA E AS MEDIAÇÕES DAS POLÍTICAS SOCIAIS}

É a partir da análise sustentada pela teoria crítica marxiana e marxista que buscamos examinar as relações sociais estabelecidas na sociedade capitalista, considerando o trabalho "[...] componente distintivo do homem como um ser prático-social, portanto, histórico, produto e criador da vida em sociedade" (IAMAMOTO, 2007, p. 201). A produção da existência, na sua continuidade, é a sua reprodução, sendo que toda esfera de reprodução é instância de produção. Há uma relação dialética entre produção e reprodução, como nos apresenta Iamamoto:

O processo de produção no seu fluxo permanente de renovação é também o seu processo de reprodução: desenvolve as forças produtivas sociais do trabalho e do capital frente ao trabalhador como riqueza alheia que o domina e é por ele produzido e reproduzido de forma ampliada. No mesmo movimento, desenvolve sua pobreza, subordinação subjetiva e inconformismo. Cresce o proletariado laborioso, ao mesmo tempo em que são criadas as condições materiais de uma vida conformada de maneira nova (IAMAMOTO, 2007, p. 30). 
Considerando a atual recomposição do ciclo de reprodução do capital, é desafio para a(o) assistente social a formação para o trabalho intelectual compreendido no processo da reestruturação produtiva, no bojo do trabalho coletivo dessa categoria profissional. Segundo Mota e Amaral (1998, p. 26), "[...] a principal tarefa do Serviço Social nos tempos atuais é a de identificar o conjunto das necessidades (políticas, sociais, materiais e culturais), quer do capital, quer do trabalho, que estão subjacentes às exigências de sua refuncionalização". Portanto, é necessário considerar a formação profissional como parte constitutiva e inerente ao exercício profissional, que exige a apropriação de competências reflexivas e abstrações da realidade social. A formação permanente deve estar comprometida em desvelar os dilemas do mundo do trabalho (e das especificidades do trabalho da(o) assistente social) contextualizando sua importância para sustentar o projeto ético-político profissional e sua própria reprodução, conforme apontam os intelectuais da categoria nas produções acadêmicas, bem como podemos abstrair dos documentos que orientam a formação e o exercício profissional por meio de suas diretrizes, tais como a lei que regulamenta a profissão (8663/96); o Código de Ética Profissional (1993) e as Diretrizes Gerais da formação profissional/ABEPSS (1996).

Sob a égide do capitalismo monopolista, ${ }^{6}$ a transformação estrutural nos processos de trabalho e, consequentemente, nas relações sociais de produção e reprodução da vida, requerem cada vez mais profissionais alienados e despidos de postura crítica. A reestruturação econômica desencadeada pela necessidade de o sistema do capital restabelecer um "novo equilíbrio", em razão de suas crises de acumulação, é marcada por um conjunto de estratégias que buscam a reorganização do processo de produção, circulação de mercadorias e realização de lucros. Para tanto, exige-se uma modificação nas regras de sociabilidade capitalista. Sob a lógica do reordenamento econômico e político, em termos mundiais, Mota esclarece:

Este movimento determina a reestruturação dos capitais, com as fusões patrimoniais, a íntima relação entre o capital industrial e financeiro, as novas composições de força no mercado internacional, além da formação de oligopólios globais via processo de concentração e descentralização do capital; e as transformações no processo de trabalho como uma exigência do reordenamento das fases do processo de produção e realização da mais-valia, fazendo emergir também outras formas de constituição e reprodução do trabalho coletivo, além de redefinir as fronteiras entre os processos de subsunção real e formal do trabalho ao capital (MOTA; AMARAL, 1998, p. 10).

Esse projeto sustenta-se tendo como aparato econômico e político um Estado que alicerça suas bases no ideário neoliberal, ${ }^{7}$ cujos princípios reafirmam a economia de mercado, o Estado mínimo para o social, e uma cultura que subordina a liberdade política à liberdade econômica. A retração do Estado para a classe trabalhadora, com baixa incidência de proteção social, somada às novas condições deletérias do mundo do trabalho, enseja um conjunto de necessidades e demandas de uma parcela significativa dos trabalhadores que, ou passam a se inserir de forma precarizada

\footnotetext{
${ }^{6}$ Segundo Netto (2009, p.19), a passagem do capitalismo concorrencial ao capitalismo monopolista no último quartel do século XIX deflagra profundas modificações no seu ordenamento e dinâmica econômica com incidências na estrutura social e nas instâncias políticas dos Estados nacionais. "[...] "o capitalismo monopolista recoloca, em um patamar mais alto, o sistema totalizante de contradições que confere à ordem burguesa os seus traços balizares de exploração, alienação e transitoriedade histórica, todos eles desvelados pela crítica marxiana".

${ }^{7}$ As imposições desse ideário para as contrarreformas do Estado respondiam aos organismos internacionais - Banco Mundial, Fundo Monetário Internacional, Organização Mundial do Comércio, Banco Interamericano de Desenvolvimento.
} 
no mercado ou encontram-se desempregados. Além disso, nesse sistema, para externalizar os custos e a produção, estimulam-se os(as) trabalhadores(as) a reconhecerem-se no trabalho "livre", em que realizam suas atividades com "total autonomia", por seus próprios meios. ${ }^{8}$ Essa estrutura afeta sobremaneira a capacidade organizativa da classe trabalhadora, enfraquecendo suas lutas coletivas e o poder sindical, uma vez que é impulsionada para o terreno econômico-corporativo.

Considerando que a sociedade se constitui no emaranhado das forças contraditórias como resultado do processo de organização e desenvolvimento do modo de produção capitalista, as expressões da questão social são acirradas. Elas tencionam projetos políticos-institucionais para realização de mediações entre o capital e o trabalho, mediante políticas públicas. Vale destacar as afirmações de Iamamoto nessa direção:

Reafirma-se, pois, a questão social como base de fundação sócio-histórica da profissão, em seu enfrentamento pelo Estado, pelo empresariado e pelas ações da classe trabalhadora no processo de constituição e afirmação dos direitos sociais, o que requer diferenciar suas multifacetadas refrações no cotidiano da vida social, que são matéria do trabalho do assistente social (IAMAMOTO, 2007, p. 183).

O Estado, ao implementar as políticas públicas, entendidas como campo privilegiado de intervenção profissional do Serviço Social, requisita a força de trabalho da(o) assistente social com o intuito de intermediar as demandas da população e o acesso aos serviços sociais. Por sua vez, à sociedade brasileira destinam-se políticas governamentais que passam ao largo de um modelo estrutural de redistribuição de riqueza, cuja lógica do sistema de arrecadações tributárias e de gestão do fundo público beira a perversidade. Além disso, instaura-se um processo de terceirização dos serviços antes ofertados pelo Estado, por meio de entidades e organizações sociais, afetando tanto a qualidade da prestação dos serviços quanto precarizando as relações de trabalho dos(as) profissionais dessa área.

Nesse cenário, há que se apreender a política social de educação na esteira desse novo padrão de "acumulação flexível de capital", bem como realizar a leitura do significado da(o) profissional do Serviço Social, que se insere na divisão sociotécnica e sexual do trabalho, como trabalhador(a) submetida(o) a todas as regras do sistema do capital. Conforme apresenta Mota e Amaral (1998, p. 29), na reestruturação produtiva em curso há “[...] uma verdadeira reforma intelectual e moral, visando à construção de uma outra cultura do trabalho e de uma nova racionalidade política e ética compatível com a sociabilidade requerida pelo projeto do capital". Portanto, à(ao) profissional do Serviço Social requisitada(o) pelo mundo do trabalho para contribuir com as condições necessárias à manutenção do processo de reprodução social da vida e, contraditoriamente, de dominação social, é indispensável que se aproprie de uma formação intelectual compatível com o conjunto de desafios impostos pelas novas condições de sociabilidade no mundo. Ressalta-se que, a partir do movimento de reconceituação, o Serviço Social assume hegemonicamente como categoria profissional uma direção social pautada na racionalidade crítico-dialética a partir de fundamentos teórico-metodológico, técnico-operativo e ético-político a favor da classe trabalhadora e na perspectiva de contribuir para a construção de outra sociabilidade. Nesse sentido, torna-se imprescindível que se aproprie de uma formação intelectual compatível com o seu projeto ético-político profissional, que possibilite desvelar as novas condições impostas pelo capital.

\footnotetext{
${ }^{8}$ Diversos são os exemplos que poderiam ser citados, mas ganhou relevância e visibilidade o que está sendo denominado de "uberização" dos serviços, conforme aponta Antunes (2019).
} 
Esse tensionamento entre formação profissional sedimentada na razão instrumental, tecnicista, acrítica, aligeirada, expressa-se no projeto educacional brasileiro e na luta por seu contrapondo, ou seja, uma educação alicerçada na racionalidade dialético-critica e na formação integral, que se impõe à categoria profissional de assistentes sociais.

\section{AS TENDÊNCIAS DA FORMAÇÃO PROFISSIONAL ARTICULADAS ÀS EXIGÊNCIAS DO MUNDO DO TRABALHO}

Para iniciarmos a problematização aqui sugerida, reportamos à citação de Iamamoto:

O projeto de formação profissional no Brasil reconhece a dimensão contraditória das demandas que se apresentam à profissão, expressão das forças sociais que nelas incidem: tanto o movimento do capital, quanto os direitos, valores e princípios que fazem parte das conquistas e do ideário dos trabalhadores (IAMAMOTO, 2007, p. 182).

É a partir deste pressuposto que sustentamos a importância do compromisso com uma formação profissional que considere os inúmeros desafios que perpassam a necessidade de refundação de um novo padrão de sociabilidade, com a defesa de valores democráticos e direitos amplos de cidadania. Segundo Sara Granermam (1999), várias profissões surgem na passagem do capitalismo concorrencial para o capitalismo monopolista. Algumas delas foram demandas para garantir o trabalho direto na esfera produtiva, outras se apresentam com a finalidade de garantir a extração de mais-valor e contribuir com a reprodução da vida social. o Serviço Social é uma profissão que surge no intuito de participar da geração das condições necessárias à manutenção do processo social de reprodução (ALMEIDA, 1996). Destaca-se, de acordo com esse autor, que o trabalho $\mathrm{da}(\mathrm{o})$ assistente social é requerido como especialidade da divisão sociotécnica do trabalho, na forma assalariada, para responder às estratégias de dominação da burguesia no enfrentamento das expressões cotidianas da questão social que emergem da diferenciação e conflito de classes. No contexto de globalização da produção, mercantilização universal e culto ao individualismo, cabe $\mathrm{a}(\mathrm{o})$ profissional do Serviço Social engendrar mediações para responder às exigências do mundo do trabalho, bem como criar estratégias para tecer respostas coletivas às expressões da questão social, seja por meio da implementação das políticas sociais, da mobilização ou da organização social, tendo como referência a luta por direitos, bem como a perspectiva de uma outra sociabilidade.

Nessa direção, é imprescindível ao profissional de Serviço Social uma formação intelectual com competência técnica, científica e ético-política para o desenvolvimento de suas funções nos diversos espaços sócio-ocupacionais. Exige-se um nível de abstração da realidade social que possa comportar tanto a compreensão sobre o exercício profissional da categoria no campo da contradição de classe quanto a ótica dos sujeitos a quem se dirige a intervenção profissional (IAMAMOTO, 2007). Em tempos de reestruturação produtiva, caracterizada principalmente pela flexibilização dos processos e condições de trabalho, a formação da(o) trabalhador(a) coletivo(a) também é alterada significativamente, com vistas a responder às determinações do sistema capitalista. As(os) trabalhadoras(es) são submetidos(as) à terceirização e precarização das relações de trabalho, ao desemprego e a vínculos extremamente fragilizados. Acrescente-se a isso uma exigência de produtividade que vem adoecendo diversas categorias profissionais. Observa-se a racionalização e enxugamento da esfera pública por meio de reordenamento dos modelos 
gerenciais que, muitas vezes, corrompem suas estruturas, procedimentos e processos diante da narrativa da crise.

De acordo com Maciel (2019), ao longo da história, o Estado brasileiro conduziu a expansão das políticas públicas, inclusive da política de educação superior, a partir de uma perspectiva elitista discriminante da classe trabalhadora, priorizando uma formação que tem como centralidade a preparação para o mercado, em detrimento da formação para a cidadania ampliada e transformadora. Essa lógica do sistema educacional alarga os abismos econômicos e culturais da sociedade, contribuindo para o aprofundamento da desigualdade social. Em outra direção, a categoria profissional coloca-se em defesa de uma formação universitária voltada para os interesses coletivos, com a finalidade de produzir e difundir conhecimento crítico com liberdade didática e científica, o que pressupõe, no mínimo, a garantia da indissociabilidade entre ensino, pesquisa e extensão; e um processo ensino e aprendizagem comprometido com os percursos formativos coerentes com os requisitos teóricos e práticos fundamentais à cada profissão.

Além disso, são inúmeros os desafios que dizem respeito às condições objetivas e subjetivas de acesso e permanência à educação superior no país. Ao impulsionar a implementação de um modelo educacional que tem como referência o setor privado e o ensino a distância, o Estado privilegia o capital..$^{9}$ Reforça a subordinação da classe trabalhadora às condições de formação profissional que buscam responder aos interesses de lucratividade e legitimação de uma cultura reprodutora de valores do mercado. Por outro lado, observa-se o endividamento dos estudantes ao contratarem recursos do Programa de Financiamento Estudantil (Fies) para garantirem sua formação. Verificamos um conjunto de incongruências que abarcam as dimensões estruturais do sistema educacional (econômica, social, cultural, regional e política), bem como os processos internos de organização curricular, passando por modelos de avaliação (como, por exemplo, o Exame Nacional de Desempenho dos Estudantes - ENADE) que impulsionam a disputa de ranking entre as grandes "empresas da educação". ${ }^{10}$ Estas, situadas no setor de serviços, assumiram e se posicionaram no mercado financeiro como grandes grupos de investidores, movimentando milhões nas bolsas de valores. O coletivo de trabalhadores desse setor, submetidos às regras e condições da reestruturação produtiva, depara-se com o desmonte de seus direitos conquistados, submetendo-se à mais intensa expropriação de sua força de trabalho, agravada pela condição de país de capitalismo dependente. Nesse mesmo sentido, sucateia-se e precariza-se a formação profissional, sob as determinações da mercantilização do ensino, passando a cumprir uma função social de reprodução de dominação e opressão da classe trabalhadora. Por sua vez, e em um ciclo vicioso, o exercício profissional passa a responder às requisições do mundo do trabalho de forma acrítica, sem apreensão da realidade em sua totalidade. Uma direção ético-política contra-hegemônica sustentada pela ideação de projeto societário equânime e justo acaba por perder espaço diante do utilitarismo e pragmatismo que absorve a profissão, muitas vezes capturada pela onda neoconservadora disseminada na sociedade brasileira.

\footnotetext{
${ }^{9}$ Pesquisa documental nos sites oficiais do governo federal - Censo de Educação Superior (CES) demonstra e explicita a vertiginosa incidência das IES privadas na oferta de vagas no ensino superior.

${ }^{10}$ De acordo com pesquisa realizada pela FGV, publicada em O Estado de São Paulo, são oito grandes grupos que ofertam $27,8 \%$ do total de vagas no ensino superior, considerando as empresas de capital aberto (Anhanguera, Ânima, Estácio, Kroton e Ser), dois grupos internacionais (DeVry e Laureate) e a Universidade Paulista (Unip), que, embora não seja um conglomerado, também controla instituições de ensino. Os dados foram extraídos do Censo do Ensino Superior - o de 2014 é o mais recente - e de formulários de referência apresentados à Comissão de Valores Mobiliários (CVM) pelas companhias (TOLEDO, 2016).
} 
De acordo com Iamamoto (2007), a(o) assistente social é produto da formação universitária, que a(o) capacita a realizar um "trabalho complexo". Sua força de trabalho, entendida como uma mercadoria, transforma-se em atividade quando aliada aos meios necessários para sua realização, que se encontram monopolizados pelos empregadores. Como trabalhadoras(es) intelectuais produtivos no campo dos serviços (seja público ou privado), devem também ocupar-se da construção de estratégias que possibilitem enfrentar os desafios do cotidiano. Para tanto, impõe-se uma formação crítica, competente e de qualidade, sustentada por bases de fundamentação teórico-metodológica e ético-políticas sólidas, que permitam apreensão da realidade social em sua totalidade. Noutro sentido, a precarização do sistema educacional, cada vez mais mercantilizado, agudiza as inconsistências da formação profissional em Serviço Social, sombreando as contradições impostas pelo sistema do capital ao próprio significado da profissão e de seu lugar na divisão sociotécnica e sexual do trabalho.

\section{CONSIDERAÇÕES FINAIS}

Procuramos desenvolver um estudo que contribuísse com as reflexões acerca de categorias consideradas fundamentais para a compreensão da dinâmica societária estabelecida no sistema do capital, identificando as tendências da formação e do exercício profissional das(os) assistentes sociais na sociedade contemporânea. A partir da categoria totalidade, propusemos um percurso teórico que abarcasse, num primeiro momento, a análise das categorias trabalho, valor e mais-valor. A intenção foi entender o significado do trabalho em suas particularidades e, principalmente, as condições em que se realiza o trabalho no campo dos serviços, tendo como objeto de reflexão o trabalho intelectual como uma dimensão do trabalho da(o) assistente social.

O esforço de problematizar sobre o trabalho no setor de serviços, em tempos de reestruturação produtiva, cujas determinações incidem diretamente sobre a classe trabalhadora em geral e, especialmente, as(os) trabalhadores(as) desse setor foi fundamental, uma vez que hoje ocupam mais da metade da força produtiva empregada no mundo (HIRANO, 2001). No Brasil, particularmente, as estruturas políticas e econômicas têm estabelecido as contrarreformas que retiram direitos sociais e trabalhistas da população e ampliam o contingente de desempregados e subempregados. Sob a lógica neoliberal, as políticas públicas assumem o caráter cada vez mais restritivo, e até punitivo, frente à concepção e modelo político-ideológico implantado pelo atual governo.

Nesse contexto, a política educacional segue o percurso de legitimação do poder e dominação das elites, garantindo melhores e mais amplas condições de acesso e permanência ao ensino superior àquelas(es) que têm mais poder aquisitivo, seja nas universidades públicas ou privadas. A política, como campo de mediação para a transformação social, enreda um conjunto de relações sociais incompatíveis com as bases societárias justas e equânimes.

As aproximações realizadas sobre a formação e o trabalho da(o) assistente social buscaram considerar as particularidades e tensões da relação entre o estatuto assalariado e o projeto ético-político profissional. Reconhecemos que o Serviço Social é uma especialização do trabalho, parte da divisão sociotécnica e sexual do trabalho social. Portanto, o trabalho da(o) assistente social deve ser tratado de forma indissociável dos enfrentamentos e lutas experimentadas pelo conjunto da classe trabalhadora, que vem perdendo seus direitos ao longo da história. A formação profissional tem ficado comprometida com a tendência de mercantilização dos serviços educacionais, uma vez que os grandes empresários buscam a valorização de seus investimentos em 
detrimento da racionalidade do ensino crítico, da pesquisa independente e da extensão solidária aos dilemas comunitários. 0 exercício profissional vem sendo requisitado por parte dos agentes empregadores (público ou privado), a partir de respostas focadas apenas na reprodução da força de trabalho, tendo em vista a lógica de dominação social do capital. Nessa direção, há uma tendência de operacionalização das políticas públicas desenvolvidas no cotidiano mediante intervenção pragmática, tecnicista, descomprometida com os direitos, a cidadania e a luta de classe.

Entendemos que só é possível uma atuação competente e crítica no Serviço Social se existir uma formação intelectual e prática em que as(os) estudantes e profissionais sejam expostos ao debate direto, à reflexão permanente, à compreensão dos processos históricos para desvelamento das mediações, reconhecendo a historicidade e as contradições sociais a partir da totalidade. A consciência crítico-dialética é forjada a partir de uma prática cotidiana e presencial que expresse possibilidades de abstração da realidade, com vistas à construção de uma intervenção profissional comprometida com uma sociabilidade alicerçada em relações equânimes no enfrentamento das expressões da questão social e na defesa do propósito da emancipação humana.

\section{REFERÊNCIAS}

ALMEIDA, N. L. T. de. Considerações iniciais para o exame do processo de trabalho do Serviço Social. Serviço Social e Sociedade. São Paulo, Cortez, ano XVII, n. 52, dez. 1996, p. 24-47.

ANTUNES, R. Da educação utilitária fordista à da multifuncionalidade liofilizada. In: Das crises do capital às crises da Educação Superior no Brasil - novos e renovados desafios em perspectiva. 1.ed. Uberlândia: Navegando Publicações, 2019. p. 5-17.

ANTUNES, R. Coronavírus: o trabalho sob fogo cruzado. 1.ed. São Paulo: Boitempo, 2020.

CHAGAS, E. F. A determinação dupla do trabalho em Marx: trabalho concreto e trabalho abstrato. Disponível em: <https://marxismo21.org/wp-content/uploads/2012/08/A-determinação-dupla...-Ed.Chagas.pdf>. Acesso em: 11 abr. 2019.

CHESNAIS, F. A mundialização do capital. São Paulo: Xamã, 1996.

COSTA, M. D. H. Os serviços sociais na contemporaneidade: notas sobre o trabalho nos serviços. In: MOTA, A. E. (org.). A Nova Fábrica de Consensos. São Paulo, Cortez, 1998, p. 97-114.

GRANEMANN, S. Processos de trabalho e Serviço Social. In: CFESS-ABEPSS-CEAD/UNB. Reprodução Social, Trabalho e Serviço Social. Módulo I. Capacitação em Serviço Social e Política Social. Brasília: CEAD, 1999. p. 153-166.

HIRANO, S. Política e economia como formas de dominação o trabalho intelectual em Marx. Tempo Social. Revista de Sociologia. v. 13. n. 2. São Paulo: USP, novembro de 2001, p. 01-20.

IAMAMOTO. M. V. Serviço Social na contemporaneidade: trabalho e formação profissional.6. ed. São Paulo: Cortez, 2003.

IAMAMOTO. M. V. Serviço Social em tempo do capital fetiche. Capital financeiro, trabalho e questão social. São Paulo: Cortez, 2007. (cap. IV).

LUKÁCS, G. A reprodução. In: Para uma ontologia do ser social II. São Paulo: Boitempo, 2013. p. 159-201. 
MACIEL, F. C. C. Política de educação e o ensino superior a distância: início de uma problematização sobre a formação em Serviço social. In: Tópicos em Políticas e Serviço Social. v. 1. Belo Horizonte: Editora Poisson, 2019, p. 150-159.

MARX, K. Contribuição a crítica da Economia Política. Tradução e introdução de Florestan Fernandes, 2. ed. São Paulo, Expressão Popular, 2008.

MARX, K. O Manifesto Comunista. Rio de Janeiro: Paz e Terra, 1996.

MEC/INEP. Censo da Educação Superior Brasileira. Relatórios Técnicos. Resumo Técnico 2018. Brasília, 2018. Disponível em: <http://download.inep.gov.br/educacao_superior/censo_superior/ documentos/2019/censo_da_educacao_superior_2018-notas_estatisticas.pdf>. Acesso em: 08 out. 2019.

MÉSZÁROS, I. A educação para além do capital. Tradução de Isa Tavares. 2. ed. São Paulo: Boitempo, 2008.

MOTA, A. E. e AMARAL, A. S. Reestruturação do Capital, fragmentação do trabalho e Serviço Social. In: A Nova Fábrica de Consensos. São Paulo: Cortez, 1998. p. 23-44.

NETTO, J. P. Capitalismo Monopolista e Serviço Social. 7. ed. São Paulo: Cortez, 2009.

ORTIZ, F. G. Serviço Social e Ética: a constituição de uma imagem social renovada. In: Ética e direitos: ensaios críticos. Coletânea nova de Serviço Social. 2. ed. São Paulo: Lúmen Júris, 2010.

PONTES, R. N. Mediação e Serviço Social. 2. ed. São Paulo: Cortez, 1997.

PONTES, R. N. Mediação: categoria fundamental para o trabalho do assistente social. In: Capacitação em Serviço Social e Políticas Sociais: Módulo 4: O Trabalho do assistente social e as políticas sociais. Brasília: CEAD, 2000.

RUBIN, I. A Teoria Marxista do Valor. São Paulo: Polis, 1987.

TOLEDO, Luiz Fernando. Só 8 grupos concentram 27,8\% das matrículas do ensino superior. 0 Estado de São Paulo, 08 de junho de 2016. Disponível em: <https://educacao.estadao.com. $\mathrm{br} /$ noticias/geral,apenas-8-grupos-privados-concentram-27-8-das-matriculas-do-ensinosuperior,10000055857https://educacao.estadao.com.br/noticias/geral,apenas-8-grupos-privadosconcentram-27-8-das-matriculas-do-ensino-superior,10000055857>. Acesso em: 08 out. 2019.

TUMOLO, P. S. As metamorfoses do mundo do trabalho: revisão de algumas linhas de análise. In: Educação \& Sociedade, ano XVIII, n. 59, 1997. 